\title{
Intake of meat and fish and risk of head-neck cancer subtypes in the Netherlands Cohort Study
}

\author{
Andy Perloy ${ }^{1}$ Denise H. E. Maasland ${ }^{1} \cdot$ Piet A. van den Brandt ${ }^{1} \cdot$ Bernd Kremer $^{2}$ • \\ Leo J. Schouten ${ }^{1}$
}

Received: 23 March 2016 / Accepted: 29 March 2017 / Published online: 5 April 2017

(C) The Author(s) 2017. This article is an open access publication

\begin{abstract}
Purpose To date, the role of meat and fish intake in headneck cancer (HNC) etiology is not well understood and prospective evidence is limited. This prompted us to study the association between meat, fish, and HNC subtypes, i.e., oral cavity cancer (OCC), oro- and hypopharyngeal cancer (OHPC), and laryngeal cancer (LC), within the Netherlands Cohort Study (NLCS).

Methods In 1986, 120,852 participants (aged 55-69 years) completed a baseline 150-item food frequency questionnaire (FFQ), from which daily meat and fish intake were calculated. After 20.3 years of follow-up, 430 HNC overall (134 OCC, 90 OHPC and 203 LC) cases and 4,111 subcohort members were found to be eligible for case-cohort analysis. Multivariate hazard ratios were calculated using Cox's proportional hazards model within quartiles of energy-adjusted meat and fish intake.

Results Processed meat intake, but not red meat intake, was positively associated with $\mathrm{HNC}$ overall $[\mathrm{HR}(\mathrm{Q} 4$ vs. $\mathrm{Q} 1)=1.46,95 \%$ CI 1.06-2.00; $p$ trend $=0.03$ ]. Among HNC subtypes, processed meat was positively associated with OCC, while no associations were found with OHPC
\end{abstract}

Electronic supplementary material The online version of this article (doi:10.1007/s10552-017-0892-0) contains supplementary material, which is available to authorized users.

Leo J. Schouten

lj.schouten@maastrichtuniversity.nl

1 Department of Epidemiology, GROW - School for Oncology and Developmental Biology, Maastricht University, Peter Debijeplein 1, 6229 HA Maastricht, The Netherlands

2 Department of Otorhinolaryngology, Head and Neck Surgery, GROW - School for Oncology and Developmental Biology, Maastricht University Medical Center, Maastricht, The Netherlands and LC. Fish intake was not associated with HNC risk. Tests for interaction did not reveal statistically significant interaction between meat, fish, and alcohol or smoking on HNC overall risk.

Conclusions In this large cohort study, processed meat intake was positively associated with $\mathrm{HNC}$ overall and HNC subtype OCC, but not with OHPC and LC.

Keywords Meat $\cdot$ Head-neck cancer $\cdot$ Prospective cohort studies $\cdot$ Risk factors $\cdot$ Fish

\section{Introduction}

Head and neck cancer (HNC) includes among other cancers of the oral cavity (OCC), oro- and hypopharynx (OHPC), and larynx (LC), with roughly $90 \%$ being squamous cell carcinomas [1]. It is well established that tobacco and alcohol are strong risk factors for HNC and interact in a multiplicative way [2]. Recent incidence trends show a rise in human papillomavirus (HPV)-related oropharyngeal cancer cases, which is another important risk factor for HNC [3].

The role of diet in the etiology of HNC is less clear and most evidence is based on case-control studies [4]. High intake of vegetables and fruit is suggested to reduce HNC risk, which was recently confirmed in a prospective study [5]. In contrast, the evidence for meat, fish, and HNC is weak and inconsistent [1].

In various case-control studies [6-8], high intakes of red and processed meat have been positively associated with HNC, which may be explained by the carcinogenic compounds found in meat [9]. However, according to a recent meta-analysis of case-control studies, only high intake of processed, but not red meat may increase the risk of HNC subtypes oral cavity and oropharyngeal cancer [10]. 
So far, few prospective studies have investigated the relationship between meat and $\mathrm{HNC}$, not showing a clear association [11-15]. Two studies [11, 12] differentiated between HNC subtypes, whereas others [13-15] only analyzed cancer of the upper digestive tract (HNC and esophageal cancer combined) and lacked sufficient cases to study HNC subtypes separately. Of the two studies that analyzed HNC subtypes, the NIH-AARP study found a positive association between red meat and laryngeal cancer [11]. In contrast, the European Prospective Investigation into Cancer and Nutrition (EPIC) study did not confirm this finding and found an increased risk of oral cavity and pharyngeal cancer with processed meat [12]. This discrepancy may be explained by differences in meat definition or levels of meat intake, and it also stresses the need for more prospective studies on this topic.

With regard to fish, case-control studies suggest that high intake of fish may reduce HNC risk [16, 17]. Fish contains long-chain omega- 3 polyunsaturated fatty acids, which may protect against certain cancers (e.g., prostate and colon cancer) according to in vitro and in vivo studies [18]. However, previous cohort studies showed no association between fish and HNC [12, 13, 19].

To further clarify the association between meat, fish, and HNC subtypes, we conducted a study within the large Netherlands Cohort Study (NLCS) consisting of Dutch men and women between 55 and 69 years at baseline (1986). It is hypothesized that $(i) \mathrm{HNC}$ risk is higher in participants with high (total, red, and processed) meat intake compared to those with low intakes; (ii) HNC risk is lower in participants with high fish intake compared to those with low intakes; (iii) the risk is different for HNC subtypes OCC, $\mathrm{OHPC}$, and LC; and (iiii) the major HNC risk factors alcohol and smoking interact with meat and fish consumption.

\section{Methods}

\section{Study population and design}

The Netherlands Cohort Study (NLCS) on diet and cancer is an ongoing prospective cohort study, initiated in 1986, with participants selected from 204 municipalities across the country. At baseline, 58,279 men and 62,573 women aged 55-69 years completed a self-administered questionnaire on dietary habits and other risk factors for cancer. Participants provided informed consent for study participation by completing and returning this questionnaire. Immediately after baseline, a subsample of 5,000 subjects was randomly selected from the full cohort for a case-cohort analysis approach. In the case-cohort design, complete data on exposures and confounders are only required for cases and subcohort members, which were chosen to efficiently process and analyze the detailed questionnaire (that also included open-ended questions). To accurately calculate the accumulated person-years of the subcohort, information on migration and vital status was firstly collected by contacting subcohort members and municipalities every 2 years and later on through linkage with the Dutch municipal population registries. Further details of the study have been described elsewhere [20]. The NLCS has been approved by the institutional review boards of the University Hospital Maastricht and TNO Nutrition and Food Research.

\section{Case identification and eligibility}

During 20.3 years of follow-up, head-neck cancer (HNC) cases in the entire cohort were identified by annually repeated record linkage to the Netherlands Cancer Registry and PALGA, the nationwide histopathology and cytopathology data network [21]. Cases were classified as proposed by Hashibe et al. [22], according to the third version of the International Classification of Diseases for Oncology (ICD-O-3) [23]. Incident, microscopically confirmed squamous cell carcinoma cases of the head and neck were included. Participants with prevalent cancer other than skin cancer were excluded at baseline. Furthermore, participants were excluded if (1) dietary data were incomplete or inconsistent and/or (2) information was missing on confounders included in the multivariate model. Finally, 430 head-neck cancer cases and 4,111 subcohort members were available for analysis. Stratified by HNC subtypes, this included 134 oral cavity (ICD-O-3 C003-009, C020-C023, C030-C031, C039-C041, C048-C050, C060-C062, C068-C069), 90 oro- and hypopharyngeal (C019, C024, C051-C052, C090-C091, C098-C104, C108-C109, C129-C132, C138-C139), and 203 laryngeal (C320-329) cancer cases; 3 cases were oral cavity/pharynx unspecified or overlapping (C028-C029, C058-C059,C140-C142, C148).

\section{Dietary and covariate assessment}

As part of the baseline questionnaire, a self-administered 150 -item food frequency questionnaire (FFQ) assessed dietary habits over the last year prior to the study. The FFQ measured (monthly/weekly) frequency and serving sizes of meat and fish consumption, from which the mean daily intake (in grams) was calculated. Based on the sum of all corresponding meat items, meats were grouped into red meat (beef, pork, minced meat, and liver), processed meat (all types of meat preserved with nitrate salt, fermentation, or smoking), and chicken. To validate the FFQ, a 9-day dietary record method was completed by a random sample from the full cohort [24]. Spearman correlation coefficients were $0.46,0.54$, and 0.53 for, respectively, the food groups namely meat, processed meat, and fish. With 
respect to possible confounders, the baseline questionnaire gathered among other information on alcohol consumption, cigarette smoking (status, duration and frequency of smoking), vegetables and fruit consumption, total energy intake, body mass index (BMI, kilograms per square meter), nonoccupational physical activity, education (four levels), and family history of $\mathrm{HNC}$.

\section{Statistical analysis}

Age- and sex-adjusted and multivariate-adjusted hazard ratios (HRs) were calculated using the Cox proportional hazards model with 95\% confidence intervals (CIs). Standard errors were estimated using a robust variance estimator to adjust for additional variance introduced by sampling a subcohort from the full cohort [25]. Time-on-study was used as the underlying time-scale and defined as time from baseline to either diagnosis of HNC, death, emigration, loss to follow-up, or censoring (December 31, 2006), whichever came first.

Daily meat and fish intakes were adjusted for total energy intake $(\mathrm{g} / 1,000 \mathrm{kcal})$ by the nutrient density method [26]. Subjects were divided into quartiles based on the sexspecific energy-adjusted intake distributions of the subcohort. For liver, chicken, and fish, there was a large group of non-consumers. Therefore, to be able to compare nonconsumers with consumers, we intentionally assigned only non-consumers to the first category of these intake variables. Consequently, consumers were divided into one of the remaining three categories by using a tertile split. Meat and fish consumption was also modeled as a continuous variable by using increments of $2.5 \mathrm{~g} / 1,000 \mathrm{kcal}$ (liver), $5 \mathrm{~g} / 1,000 \mathrm{kcal}$ (processed meat), $10 \mathrm{~g} / 1,000 \mathrm{kcal}$ (fish, minced meat and chicken), $15 \mathrm{~g} / 1,000 \mathrm{kcal}$ (beef and pork), and $20 \mathrm{~g} / 1,000 \mathrm{kcal}$ (red meat). As previously described by Steffen et al. [12], these increments correspond approximately to the standard deviation from the mean value of each intake variable.

A priori confounders were age, sex, alcohol consumption (g/day), cigarette smoking status (never/former/current), frequency of cigarettes smoked per day, duration of smoking (years), and total energy intake ( $\mathrm{kcal} / \mathrm{day})$. The continuous variables including cigarette smoking frequency and duration of smoking were centered in multivariateadjusted models [27]. Potential confounders were assessed by backward elimination and included in the final model if the hazard ratio changed by more than $10 \%$. BMI $\left(\mathrm{kg} / \mathrm{m}^{2}\right)$, non-occupational physical activity ( $\mathrm{min} / \mathrm{day}$ ), level of education (four categories), family history of HNC (yes/no), and vegetable and fruit intake $(\mathrm{g} / 1,000 \mathrm{kcal})$ were considered as potential confounders, but were not included in the final model according to this change-in-estimate criterion.
Tests for interaction were performed to examine effect modification by sex, alcohol, or cigarette smoking on HNC overall risk. For this purpose, alcohol intake was categorized into non-user, $0-15 \mathrm{~g} /$ day and $\geq 15 \mathrm{~g} /$ day and cigarette smoking was categorized as never, former, and current smoker. Hazard ratios for each stratum were calculated by adding cross-product terms between sex, alcohol or cigarette smoking and meat or fish in multivariate Cox models. The Wald test was used to test the significance of these interactions. We found no evidence for effect modification by sex ( $p$ for interaction $>0.05$ for meat and fish) and therefore sexes were combined for analysis.

To test for a dose-response relationship across quartiles of meat and fish intake, tests for trend were performed by using the sex-specific energy-adjusted median of each quartile as a continuous variable. Heterogeneity between HNC subtypes was examined by using a bootstrap method developed for the case-cohort design [28]. Further details of this method have been described in detail elsewhere [2].

In sensitivity analyses, we tested for reverse causation by excluding cases in the first 2 years of follow-up. We also tested the effects of mutual adjustment for meat (e.g., processed meat adjusted for red meat and chicken). The proportional hazards ( $\mathrm{PH})$ assumption was assessed by using the scaled Schoenfeld residuals [29]. To further examine a possible violation, a smoothed residuals plot [30] and log-minus-log plot [31] were graphically assessed. With respect to $\mathrm{HNC}$ overall, the $\mathrm{PH}$ assumption was possibly violated for the current smoker covariate (that statistically significant interacted with time). Graphical assessment of the smoothed Schoenfeld residuals plot and log-minus-log plot did not show clear evidence of a violation. To verify this, a time-varying covariate (tvc) for current smoker was included in the model, which did not affect the hazard ratios. Hence, analysis was performed without tvc for current smoker. In case the PH assumption was violated for an exposure of interest, hazard ratios were calculated for different time periods $(0-5,5-10$, and $>10$ years) of follow-up to see how the hazard ratio changed over time.

All statistical analyses were performed with STATA (version 13.1, StataCorp LP, College Station, TX, USA) and reported $p$ values were two-sided, with $p<0.05$ considered statistically significant.

\section{Results}

\section{Baseline characteristics}

In Table 1, baseline characteristics for cases and subcohort members are given, with dietary intake variables reported as nutrient density-adjusted variables $(\mathrm{g} / 1,000 \mathrm{kcal})$. The mean age in the subcohort was 61.3 years. HNC cases, as 
Table 1 Baseline characteristics of eligible subcohort members and head-neck cancer cases in the Netherlands Cohort Study (1986-2006)

\begin{tabular}{|c|c|c|c|c|c|}
\hline \multirow[t]{2}{*}{ Baseline characteristics } & \multirow[t]{2}{*}{ Subcohort $(n=4,111)$} & \multicolumn{4}{|l|}{ Head-neck cancer cases } \\
\hline & & HNC overall $(n=430)$ & OCC $(n=134)$ & OHPC $(n=90)$ & $\mathrm{LC}(n=203)$ \\
\hline Age (years) mean (SD) & $61.3(4.2)$ & $61.6(4.1)$ & $61.9(4.2)$ & $61.5(4.0)$ & $61.5(4.0)$ \\
\hline Sex: men $(\%)$ & 49.2 & 77.7 & 57.5 & 74.4 & 93.1 \\
\hline Red meat $(\mathrm{g} / 1,000 \mathrm{kcal})$ mean $(\mathrm{SD})^{\mathrm{a}}$ & $46.9(22.9)$ & $46.0(21.5)$ & $47.6(22.3)$ & $44.2(22.9)$ & $45.6(20.4)$ \\
\hline Men & $44.6(21.0)$ & $45.1(19.5)$ & $46.1(17.6)$ & $41.6(18.6)$ & $46.0(20.5)$ \\
\hline Women & $49.2(24.3)$ & $49.0(27.2)$ & $49.7(27.4)$ & $51.5(31.7)$ & $41.1(19.7)$ \\
\hline Processed meat (g/1,000 kcal) mean (SD) & $6.5(6.6)$ & $7.3(7.0)$ & $7.2(6.6)$ & $6.6(5.9)$ & $7.8(7.6)$ \\
\hline Men & $7.0(6.8)$ & $7.5(6.7)$ & $7.4(6.7)$ & $6.8(5.8)$ & $7.8(7.0)$ \\
\hline Women & $6.1(6.4)$ & $6.8(7.8)$ & $6.9(6.5)$ & $6.0(6.4)$ & $7.7(13.6)$ \\
\hline Fish $(\mathrm{g} / 1,000 \mathrm{kcal})^{\mathrm{b}}$ & $7(0-10)$ & $7(2-10)$ & $8(1-10)$ & $9(2-12)$ & $7(2-10)$ \\
\hline $\operatorname{Beef}(\mathrm{g} / 1,000 \mathrm{kcal})^{\mathrm{b}}$ & $14(5-20)$ & $14(5-19)$ & $16(5-21)$ & $12(5-17)$ & $13(5-18)$ \\
\hline Pork $(\mathrm{g} / 1,000 \mathrm{kcal})^{\mathrm{b}}$ & $20(9-28)$ & $20(9-27)$ & $19(8-26)$ & $20(8-29)$ & $20(9-27)$ \\
\hline Minced meat $(\mathrm{g} / 1,000 \mathrm{kcal})^{\mathrm{b}}$ & $10(4-14)$ & $10(4-13)$ & $10(4-13)$ & $10(4-13)$ & $10(4-14)$ \\
\hline Liver consumers $(\%)$ & 35.9 & 43.0 & 43.0 & 45.6 & 41.9 \\
\hline Liver consumers: intake $(\mathrm{g} / 1,000 \mathrm{kcal})^{\mathrm{b}}$ & $3(1-4)$ & $3(1-4)$ & $3(1-4)$ & $3(1-5)$ & $3(1-3)$ \\
\hline Chicken $(\mathrm{g} / 1,000 \mathrm{kcal})^{\mathrm{b}}$ & $7(2-10)$ & $6(2-9)$ & $7(2-11)$ & $7(2-10)$ & $6(2-9)$ \\
\hline Fruit consumption $(\mathrm{g} / 1,000 \mathrm{kcal})^{\mathrm{b}}$ & $97(49-130)$ & $71(24-99)$ & $106(52-142)$ & $66(16-85)$ & $68(25-97)$ \\
\hline Vegetables consumption $(\mathrm{g} / 1,000 \mathrm{kcal})^{\mathrm{b}}$ & $107(71-131)$ & $97(62-118)$ & $108(74-131)$ & $95(56-120)$ & $90(59-111)$ \\
\hline Energy intake (kcal/day) mean (SD) & $1,927(513)$ & $2,053(550)$ & $1,885(589)$ & $2,063(470)$ & $2,168(526)$ \\
\hline Men & $2,169(509)$ & $2,175(513)$ & $2,102(566)$ & $2,184(437)$ & $2,205(514)$ \\
\hline Women & $1,692(395)$ & $1,630(462)$ & $1,592(487)$ & $1,710(384)$ & $1,671(440)$ \\
\hline BMI $\left(\mathrm{kg} / \mathrm{m}^{2}\right)$ mean $(\mathrm{SD})$ & $25.0(3.1)$ & $24.8(2.7)$ & $24.9(3.0)$ & $24.4(2.6)$ & $25.0(2.6)$ \\
\hline \multicolumn{6}{|l|}{ Level of education (\%) } \\
\hline Primary school & 28.2 & 27.9 & 21.6 & 22.5 & 33.8 \\
\hline Lower vocational & 22.0 & 17.8 & 16.4 & 19.1 & 18.4 \\
\hline High school & 35.6 & 35.1 & 39.6 & 37.1 & 31.8 \\
\hline Higher vocational/university & 14.2 & 19.2 & 22.4 & 21.4 & 15.9 \\
\hline $\begin{array}{l}\text { Physical activity, non-occupational } \\
(\min / \text { day })^{\text {b }}\end{array}$ & 73 (34-94) & $71(34-90)$ & $67(34-86)$ & $67(30-88)$ & 75 (39-94) \\
\hline \multicolumn{6}{|l|}{ Cigarette smoking status (\%) } \\
\hline Never smoker & 36.9 & 13.5 & 29.1 & 7.8 & 5.9 \\
\hline Former smoker & 36.0 & 29.5 & 25.4 & 28.9 & 33.0 \\
\hline Current smoker & 27.1 & 57.0 & 45.5 & 63.3 & 61.1 \\
\hline \multicolumn{6}{|l|}{ Ever cigarette smokers } \\
\hline Frequency of cigarette smoking ( $n /$ day) & $15.3(10.3)$ & $19.5(10.8)$ & $20.4(11.8)$ & $21.1(12.6)$ & $18.4(9.4)$ \\
\hline Duration of cigarette smoking (years) & $31.6(12.3)$ & $38.7(9.8)$ & $36.9(10.0)$ & $38.1(10.2)$ & $39.9(9.6)$ \\
\hline Pack-years of cigarette smoking $(n)$ & $22.6(17.7)$ & $34.2(21.0)$ & $34.9(23.4)$ & $36.3(23.3)$ & $33.0(18.7)$ \\
\hline Alcohol consumers $(\%)$ & 76.3 & 89.5 & 90.3 & 86.7 & 90.2 \\
\hline $\begin{array}{l}\text { Alcohol consumers: ethanol intake (g/ } \\
\text { day) mean (SD) }\end{array}$ & $13.5(15.0)$ & $26.8(26.1)$ & $27.0(27.4)$ & $35.2(31.3)$ & $23.1(21.9)$ \\
\hline Family history of HNC (\%) & 1.9 & 1.9 & 1.5 & 1.1 & 2.0 \\
\hline
\end{tabular}

$H N C$ head-neck cancer, $O C C$ oral cavity cancer, $O H P C$ oro- and hypopharyngeal cancer, $L C$ laryngeal cancer, $S D$ standard deviation ${ }^{\mathrm{a}}$ Weight of red meat is based on raw meat weights

${ }^{\mathrm{b}}$ The median and interquartile range are shown, because of a right-skewed distribution

compared to subcohort members, were predominantly men (especially LC cases; 93.1\%). In the subcohort, the mean (SD) daily intake of red meat and processed meat was, respectively, 46.9 (22.9) and 6.5 (6.6) g/1,000 kcal. Female
LC cases had lower daily red meat intake compared to that of female subcohort members and other female HNC subtype cases. Overall, the mean daily intake of red meat and processed meat did not differ meaningfully between 
subcohort members and cases. As compared to subcohort members, cases were more likely to be consumers of liver. Mean daily intake of fruit and vegetables was lower among cases than subcohort members, except for OCC cases. Furthermore, cases were more likely current smokers and more often consumers of alcohol. Moreover, cases who consumed alcohol had a higher mean daily intake of alcohol as compared to alcohol consumers from the subcohort.

\section{Main analyses}

Results of the age- and sex-adjusted analysis (Supplemental Table S1) were generally comparable to that of the multivariate analysis, but hazard ratios were generally lower in the multivariate model.

No associations were found between a high intake of red meat and HNC risk in multivariate analysis (Table 2). High intake of processed meat was positively associated with HNC overall and HNC subtype OCC. Comparing the highest with the lowest quartile of processed meat intake, results were statistically significant in both HNC overall (HR 1.46, 95\% CI 1.06-2.00; $p$ trend $=0.03$ ) and OCC (HR 1.88, 95\% CI 1.11-3.18; $p$ trend $=0.04$ ). After processed meat was analyzed as a continuous variable ( $5 \mathrm{~g} / 1,000 \mathrm{kcal}$ increment), a statistically significant positive association was found only in OCC (HR 1.13, 95\% CI 1.00-1.27). No association was found between processed meat and OHPC. For LC, increased hazard ratios were observed with processed meat intake, but they did not reach statistical significance and no statistically significant trend across quartiles of processed meat intake was observed. High intake of fish was not associated with HNC risk.

Multivariate analysis of individual meats (Table 2) showed no association between high intake of beef and HNC risk. When comparing the highest with the lowest quartile of pork intake, a statistically significant inverse association was found between pork and OCC (HR 0.52, 95\% CI 0.29-0.92). No statistically significant inverse trend across quartiles of pork intake was observed. When tested as a continuous variable ( $15 \mathrm{~g} / 1,000 \mathrm{kcal}$ increment), pork remained statistically significantly inversely associated with OCC (HR 0.84, 95\% CI 0.71-1.00). Pork was not associated with HNC overall, OHPC, and LC. High intake of minced meat was not associated with $\mathrm{HNC}$ risk. Liver was consistently positive, but not statistically significantly associated with HNC risk. With respect to chicken, point estimates (Q4 vs. Q1 and continuous) were consistently below unity, but never reached statistically significant levels.

Tests for heterogeneity showed no statistically significant difference between HNC subtypes except for beef continuously analyzed (data not shown).

\section{Interaction with alcohol and smoking}

Within the subgroup former smokers, those in the highest quartile of red meat intake had a statistically significant decreased risk of HNC overall (Supplemental Figure S1; HR 0.54 , 95\% CI 0.32-0.91). The test for multiplicative interaction between cigarette smoking status and quartiles of red meat intake revealed no statistically significant interaction ( $p$ for interaction $=0.13$ ). Among current smokers, those in the 3rd quartile of fish intake had a statistically significant increased risk of HNC overall (Supplemental Figure S2; HR 1.69, 95\% CI 1.07-2.66). No statistically significant multiplicative interaction was observed between cigarette smoking status and quartiles of fish intake ( $p$ for interaction $=0.17$ ). Participants who drank $\geq 15$ grams of alcohol per day and were in the highest quartile of processed meat intake had a statistically significant increased risk of HNC overall (Supplemental Figure S3; HR 1.76, 95\% CI 1.07-2.91). The test for multiplicative interaction between alcohol consumption and quartiles of processed meat intake did not show statistically significant interaction ( $p$ for interaction $=0.39)$.

No statistically significant multiplicative interactions were found between quartiles of either red meat or fish and alcohol consumption (data not shown; Supplemental Figures S4 to S5). Also, intake of processed meat did not statistically significantly interact with cigarette smoking status (data not shown; Supplemental Figure S6).

\section{Sensitivity analyses}

In sensitivity analyses, we tested for reverse causation by excluding cases in the first two years of follow-up. However, this did not impact the results (data not shown). We also tested the effects of mutual adjustment for meat intake, but results remained unchanged (data not shown).

\section{Discussion}

In this large prospective study of 120,852 men and women, high intake of processed meat, but not red meat, was positively associated with HNC overall. Among HNC subtypes, processed meat was positively associated with OCC, while no associations were found with OHPC and LC. High intake of fish was not associated with HNC risk. Individual meats showed no clear associations with HNC risk. Finally, alcohol and smoking did not modify the association between meat or fish and HNC overall risk.

Various case-control studies have investigated the red meat-HNC relationship, finding inconsistent results [4, 10]. Moreover, studies did not always clearly define red meat. In our study, red meat included all types of red meat 


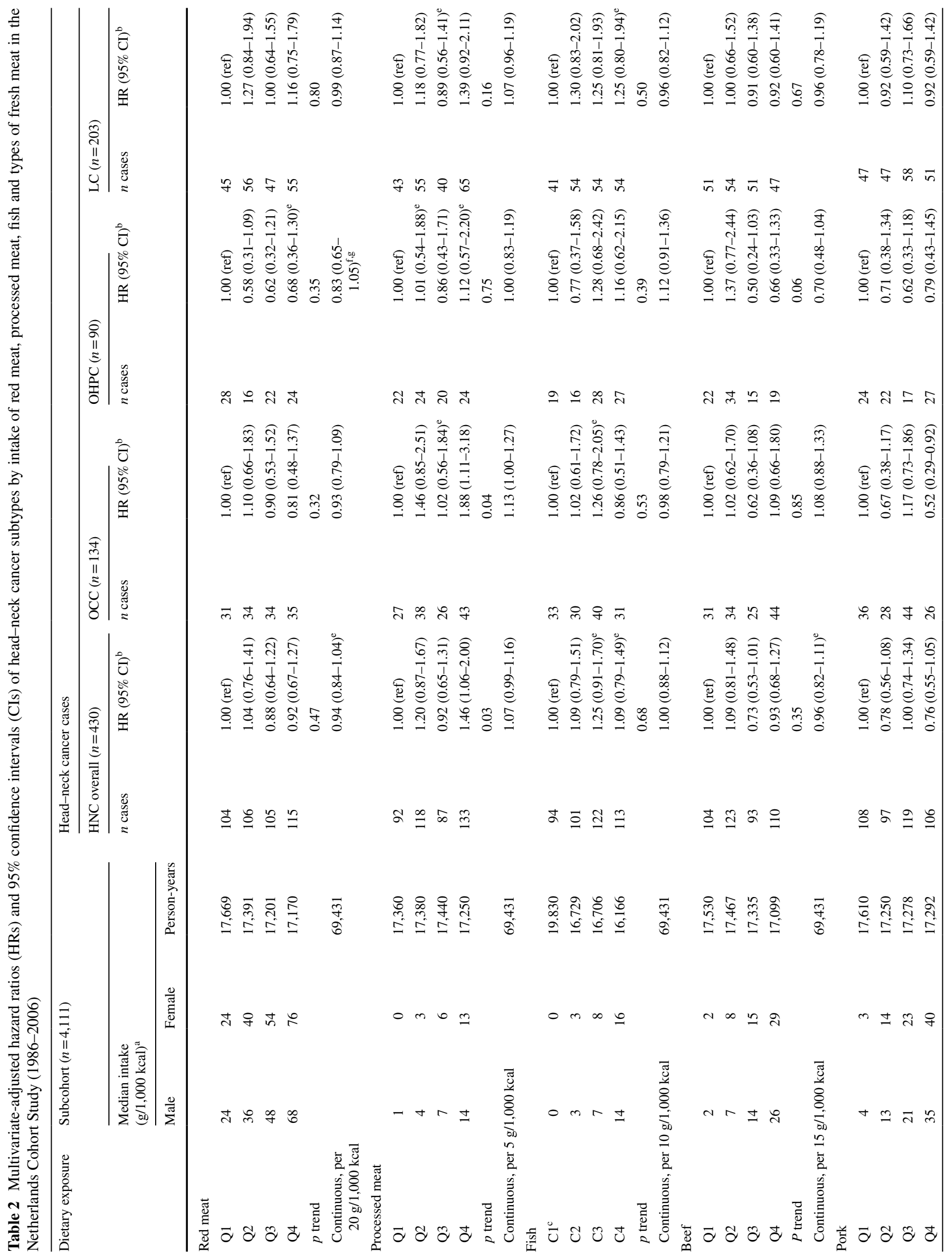




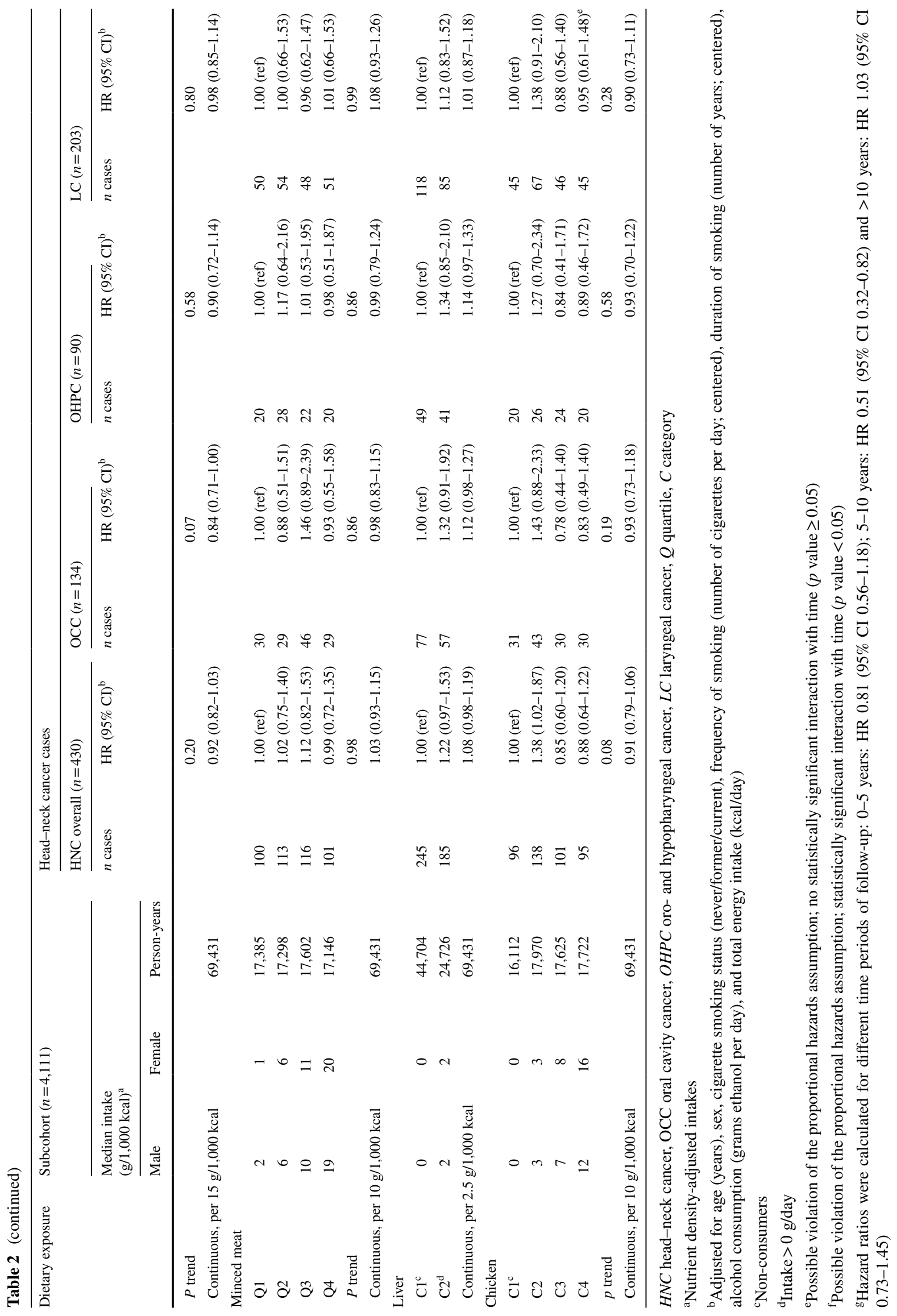


except processed red meat. Few other prospective studies examined the association between red meat and HNC [11, 12]. In the NIH-AARP study [11], red meat included processed red meat, which appeared to increase the risk of LC $[\mathrm{HR}(\mathrm{Q} 5$ vs. Q1) $=1.43,95 \%$ CI 0.99-2.07]. However, after they excluded processed red meat in sensitivity analysis, it was not mentioned whether this result persisted. Similar to our results, the EPIC study [12] did not find an association with red meat. Thus, based on results from prospective observational studies, there seems to be no clear evidence for a positive association between red meat and HNC.

We observed a positive association between processed meat and $\mathrm{HNC}$ overall $[\mathrm{HR}(\mathrm{Q} 4$ vs. Q1) $=1.46,95 \% \mathrm{CI}$ 1.06-2.00]. In the EPIC study [12], a positive association was found between processed meat and cancer of the upper aerodigestive tract (UADT). With regard to HNC subtypes, processed meat was positively associated with OCC in our study. In a meta-analysis of case-control studies [10], processed meat was positively associated with OCC and oropharyngeal cancer combined, but these HNC subtypes were not separately analyzed as was done in our study. The two other prospective studies [11, 12] also combined OCC with (oro-)pharyngeal cancer. In the NIH-AARP study [11], no association was found between processed meat and OCC and pharyngeal cancer combined, while the EPIC study [12] showed a positive association for this relationship. For HNC subtypes OHPC and LC, we did not find any association with processed meat. With regard to $\mathrm{LC}$, the two other prospective studies also found no clear association with processed meat [11, 12]. Despite the fact the processed meat was differentially associated with HNC subtypes in our study, we did not observe statistically significant heterogeneity among HNC subtypes (except for beef; continuously analyzed). This may be due to a lack of power in our analysis.

No associations between fish and HNC were found in this study, which is in line with other prospective cohort studies $[12,13,19]$. However, these studies and our study did not differentiate between the types of fish (lean/fatty fish) consumed. Consequently, this may have influenced results and limited interpretation with regard to fish and HNC [32].

With respect to individual meats, we found no associations between beef and HNC. In contrast, one other cohort study found a positive association between beef and cancer of the UADT [13]. That study, however, included 71 cases and intake was only measured by frequency of consumption. For pork, we found an unexpected inverse association with OCC, which may reflect a chance finding. In case-control studies, pork was positively associated with HNC overall [4]. The consumption of liver was consistently positive but not statistically significantly associated with HNC in our study. Other studies found inconsistent results for liver [33, 34]. We did not find an association between chicken and HNC, which is in line with results of the EPIC study [12]. In the NIH-AARP study, intake of chicken was inversely associated with LC, but in women only [19]. Overall, there appears to be no clear evidence for associations between individual meats and HNC.

We found no evidence for an interaction between meat, fish and alcohol or smoking on HNC overall risk. However, we observed an increased $\mathrm{HNC}$ overall risk for participants who drank $\geq 15 \mathrm{~g}$ of alcohol per day and were in the upper quartile of processed meat intake. Given the low number of cases across strata (especially in the non-users stratum), we possibly had limited power to detect a significant deviation from the multiplicative model. Also, an inverse association with HNC overall was shown for former smokers that were in the highest quartile of red meat intake, which we cannot explain and may possibly reflect a chance finding. In contrast to our results, the EPIC study found high intake of processed meat to be positively associated with cancer of the UADT among smokers [12]. No other prospective cohort studies have examined the interaction between meat, fish and alcohol or smoking on HNC overall risk.

Two mechanisms have been described that relate high intake of processed meat to the development of various cancers. First, processed meat contains nitrate and nitrite, which leads to the (exogenous) formation of $N$-nitroso compounds that may have carcinogenic effects [35]. Second, processed meat contains several carcinogenic substances (such as heterocyclic amines and polycyclic aromatic hydrocarbons), which can be formed during hightemperature cooking [36]. However, the latter mechanism also applies to red meat, for which we found no association with HNC. Furthermore, the (endogenous) formation of $\mathrm{N}$-nitroso compounds is also possible for red meat, which is influenced by its haem content [9]. Therefore, the previously discussed mechanisms do not clearly explain our findings regarding processed meat intake. While there is still limited prospective evidence for a positive association between processed meat and $\mathrm{HNC}$, it is probably too premature to speculate about other possible mechanisms that may explain our findings. However, our result regarding processed meat at least suggests that processed meat as compared to red meat contains specific carcinogenic substances that may contribute to an increased HNC risk.

The strengths of our study are the prospective nature, the detailed baseline assessment of exposures and covariates, the (>96\%) completeness [37] and duration of cancer follow-up, and a sufficient number of HNC (subtype) cases available for analysis. Of course, we also have to take our study limitations into account. First, participants completed a one-time baseline questionnaire and could have changed their dietary pattern during follow-up, possibly resulting in misclassification of meat intake. However, the FFQ in our 
study has been shown to reflect dietary intake over (at least) a 5-year period [38]. Second, we cannot rule out residual confounding from measured covariates, although important HNC confounders such as alcohol consumption and smoking were intensively addressed by our questionnaire. In addition, we have to consider the possibility of residual confounding from unmeasured confounders, such as HPV infection [2]. HPV, however, is especially associated with oropharyngeal cancer [39] and it is doubtful whether meat intake would have correlated with HPV exposure in this study.

In summary, in this large Dutch cohort study, processed meat was positively associated with $\mathrm{HNC}$ overall and HNC subtype OCC, but not with OHPC and LC. Future prospective studies on meat intake and HNC (subtypes) are needed to elaborate on our findings.

Acknowledgments The authors would like to thank participants of the Netherlands Cohort Study (NLCS), The Netherlands Cancer Registry (IKNL), and the Netherlands nationwide histopathology and cytopathology data network (PALGA). We would also like to thank Dr. A. Kester and Dr. A. Volovics for statistical advice; S. van de Crommert, H. Brants, J. Nelissen, C. de Zwart, M. Moll, W. van Dijk, M. Jansen, and A. Pisters for assistance; and H. van Montfort, T. van Moergastel, L. van den Bosch, R. Schmeitz from Maastricht University for programming assistance. Finally, we would like to thank Dr. R. A. Goldbohm for her contributions in the design of the NLCS. The study was funded by World Cancer Research Fund International (WCRF) and Wereld Kanker Onderzoeks Fonds (WCRF NL) (grand number: 2010/253).

\section{Compliance with ethical standards}

Conflict of interest All authors have no conflict of interest to report.

Open Access This article is distributed under the terms of the Creative Commons Attribution 4.0 International License (http:// creativecommons.org/licenses/by/4.0/), which permits unrestricted use, distribution, and reproduction in any medium, provided you give appropriate credit to the original author(s) and the source, provide a link to the Creative Commons license, and indicate if changes were made.

\section{References}

1. World Cancer Research Fund, American Institute for Cancer Research (2007) Food, nutrition, physical activity and the prevention of cancer: a global perspective. American Institute for Cancer Research, Washington, DC pp 245-249.

2. Maasland DH, van den Brandt PA, Kremer B, Goldbohm RA, Schouten LJ (2014) Alcohol consumption, cigarette smoking and the risk of subtypes of head-neck cancer: results from the Netherlands Cohort Study. BMC Cancer 14:187. doi:10.1186/1471-2407-14-187

3. Chaturvedi AK, Engels EA, Pfeiffer RM, Hernandez BY, Xiao W, Kim E, Jiang B, Goodman MT, Sibug-Saber M, Cozen W, Liu L, Lynch CF, Wentzensen N, Jordan RC, Altekruse S, Anderson WF, Rosenberg PS, Gillison ML (2011) Human papillomavirus and rising oropharyngeal cancer incidence in the
United States. J Clin Oncol 29(32):4294-4301. doi:10.1200/ jco.2011.36.4596

4. Chuang SC, Jenab M, Heck JE, Bosetti C, Talamini R, Matsuo K, Castellsague X, Franceschi S, Herrero R, Winn DM, La Vecchia C, Morgenstern H, Zhang ZF, Levi F, Dal Maso L, Kelsey K, McClean MD, Vaughan T, Lazarus P, Muscat J, Ramroth H, Chen C, Schwartz SM, Eluf-Neto J, Hayes RB, Purdue M, Boccia S, Cadoni G, Zaridze D, Koifman S, Curado MP, Ahrens W, Benhamou S, Matos E, Lagiou P, SzeszeniaDabrowska N, Olshan AF, Fernandez L, Menezes A, Agudo A, Daudt AW, Merletti F, Macfarlane GJ, Kjaerheim K, Mates D, Holcatova I, Schantz S, Yu GP, Simonato L, Brenner H, Mueller H, Conway DI, Thomson P, Fabianova E, Znaor A, Rudnai P, Healy CM, Ferro G, Brennan P, Boffetta P, Hashibe M (2012) Diet and the risk of head and neck cancer: a pooled analysis in the INHANCE consortium. Cancer Causes Control 23(1):69-88. doi:10.1007/s10552-011-9857-x

5. Maasland DH, van den Brandt PA, Kremer B, Goldbohm RA, Schouten LJ (2015) Consumption of vegetables and fruits and risk of subtypes of head-neck cancer in the Netherlands Cohort Study. Int J Cancer 136(5):E396-E409. doi:10.1002/ijc.29219

6. Levi F, Pasche C, La Vecchia C, Lucchini F, Franceschi S, Monnier P (1998) Food groups and risk of oral and pharyngeal cancer. Int J Cancer 77(5):705-709

7. Bosetti C, La Vecchia C, Talamini R, Negri E, Levi F, Dal Maso L, Franceschi S (2002) Food groups and laryngeal cancer risk: a case-control study from Italy and Switzerland. Int J Cancer 100(3):355-360. doi:10.1002/ijc.10485

8. Aune D, De Stefani E, Ronco A, Boffetta P, Deneo-Pellegrini H, Acosta G, Mendilaharsu M (2009) Meat consumption and cancer risk: a case-control study in Uruguay. Asian Pac J Cancer Prev 10(3):429-436

9. Demeyer D, Mertens B, De Smet S, Ulens M (2015) Mechanisms linking colorectal cancer to the consumption of (processed) red meat: a review. Crit Rev Food Sci Nutr 56:27472766. doi:10.1080/10408398.2013.873886

10. Xu J, Yang XX, Wu YG, Li XY, Bai B (2014) Meat consumption and risk of oral cavity and oropharynx cancer: a metaanalysis of observational studies. PLoS ONE 9(4):e95048. doi:10.1371/journal.pone.0095048

11. Cross AJ, Leitzmann MF, Gail MH, Hollenbeck AR, Schatzkin A, Sinha R (2007) A prospective study of red and processed meat intake in relation to cancer risk. PLoS Med 4(12):e325. doi:10.1371/journal.pmed.0040325

12. Steffen A, Bergmann MM, Sanchez MJ, Chirlaque MD, Jakszyn P, Amiano P, Quiros JR, Barricarte Gurrea A, Ferrari P, Romieu I, Fedirko V, Bueno-de-Mesquita HB, Siersema PD, Peeters PH, Khaw KT, Wareham N, Allen NE, Crowe FL, Skeie G, Hallmanns G, Johansson I, Borgquist S, Ericson U, Egeberg R, Tjonneland A, Overvad K, Grote V, Li K, Trichopoulou A, Oikonomidou D, Pantzalis M, Tumino R, Panico S, Palli D, Krogh V, Naccarati A, Mouw T, Vergnaud AC, Norat $\mathrm{T}$, Boeing $\mathrm{H}$ (2012) Meat and heme iron intake and risk of squamous cell carcinoma of the upper aero-digestive tract in the European Prospective Investigation into Cancer and Nutrition (EPIC). Cancer Epidemiol Biomark Prev 21(12):21382148. doi:10.1158/1055-9965.epi-12-0835

13. Kjaerheim K, Gaard M, Andersen A (1998) The role of alcohol, tobacco, and dietary factors in upper aerogastric tract cancers: a prospective study of 10,900 Norwegian men. Cancer Causes Control 9(1):99-108

14. Chyou PH, Nomura AM, Stemmermann GN (1995) Diet, alcohol, smoking and cancer of the upper aerodigestive tract: a prospective study among Hawaii Japanese men. Int J Cancer 60(5):616-621 
15. Zheng W, Sellers TA, Doyle TJ, Kushi LH, Potter JD, Folsom AR (1995) Retinol, antioxidant vitamins, and cancers of the upper digestive tract in a prospective cohort study of postmenopausal women. Am J Epidemiol 142(9):955-960

16. Notani PN, Jayant K (1987) Role of diet in upper aerodigestive tract cancers. Nutr Cancer 10(1-2):103-113. doi:10.1080/01635588709513945

17. Rajkumar T, Sridhar H, Balaram P, Vaccarella S, Gajalakshmi V, Nandakumar A, Ramdas K, Jayshree R, Muñoz N, Herrero R, Franceschi S, Weiderpass E (2003) Oral cancer in Southern India: the influence of body size, diet, infections and sexual practices. Eur J Cancer Prev 12(2):135-143

18. Weylandt KH, Serini S, Chen YQ, Su H-M, Lim K, Cittadini A, Calviello $G$ (2015) Omega-3 polyunsaturated fatty acids: the way forward in times of mixed evidence. BioMed Res Int 2015:143109. doi:10.1155/2015/143109

19. Daniel CR, Cross AJ, Graubard BI, Hollenbeck AR, Park Y, Sinha R (2011) Prospective investigation of poultry and fish intake in relation to cancer risk. Cancer Prev Res 4 (11):19031911. doi:10.1158/1940-6207.capr-11-0241

20. van den Brandt PA, Goldbohm RA, van 't Veer P, Volovics A, Hermus RJ, Sturmans F (1990) A large-scale prospective cohort study on diet and cancer in The Netherlands. J Clin Epidemiol 43(3):285-295

21. van den Brandt PA, Schouten LJ, Goldbohm RA, Dorant E, Hunen PM (1990) Development of a record linkage protocol for use in the Dutch cancer registry for epidemiological research. Int J Epidemiol 19(3):553-558

22. Hashibe M, Brennan P, Benhamou S, Castellsague X, Chen C, Curado MP, Dal Maso L, Daudt AW, Fabianova E, Fernandez L, Wunsch-Filho V, Franceschi S, Hayes RB, Herrero R, Koifman S, La Vecchia C, Lazarus P, Levi F, Mates D, Matos E, Menezes A, Muscat J, Eluf-Neto J, Olshan AF, Rudnai P, Schwartz SM, Smith E, Sturgis EM, Szeszenia-Dabrowska N, Talamini R, Wei Q, Winn DM, Zaridze D, Zatonski W, Zhang ZF, Berthiller J, Boffetta P (2007) Alcohol drinking in never users of tobacco, cigarette smoking in never drinkers, and the risk of head and neck cancer: pooled analysis in the International Head and Neck Cancer Epidemiology Consortium. J Natl Cancer Inst 99(10):777-789. doi:10.1093/jnci/djk179

23. Fritz A, Percy C, Jack A, Shanmugaratnam K, Sobin L, Parkin DM, Whelan S (eds) (2000) International classification of diseases for oncology: ICD-O, 3rd edn. World Health Organization, Geneva

24. Goldbohm RA, van den Brandt PA, Brants HA, van't Veer P, Al M, Sturmans F, Hermus RJ (1994) Validation of a dietary questionnaire used in a large-scale prospective cohort study on diet and cancer. Eur J Clin Nutr 48(4):253-265
25. Lin DY, Wei LJ (1989) The Robust inference for the cox proportional hazards model. J Amer Stat Assoc 84(408):1074-1078. doi:10.1080/01621459.1989.10478874

26. Willett WC (1998) Nutritional epidemiology. 2nd edn Oxford University Press, New York

27. Leffondre K, Abrahamowicz M, Siemiatycki J, Rachet B (2002) Modeling smoking history: a comparison of different approaches. Am J Epidemiol 156(9):813-823

28. Wacholder S, Gail MH, Pee D, Brookmeyer R (1989) Alternative variance and efficiency calculations for the case-cohort design. Biometrika 76(1):117-123. doi:10.1093/biomet/76.1.117

29. Schoenfeld D (1982) Partial residuals for the proportional hazards regression model. Biometrika 69(1):239-241. doi:10.1093/ biomet/69.1.239

30. Grambsch PM, Therneau TM (1994) Proportional hazards tests and diagnostics based on weighted residuals. Biometrika 81(3):515-526. doi:10.1093/biomet/81.3.515

31. Cleves MA, Gould WW, Gutierrez RG, Marchenko YU (2010) An introduction to survival analysis using stata. Stata Press, College Station

32. Larsson SC, Kumlin M, Ingelman-Sundberg M, Wolk A (2004) Dietary long-chain n-3 fatty acids for the prevention of cancer: a review of potential mechanisms. Am J Clin Nutr 79(6):935-945

33. De Stefani E, Boffetta P, Ronco AL, Correa P, Oreggia F, DeneoPellegrini H, Mendilaharsu M, Leiva J (2005) Dietary patterns and risk of cancer of the oral cavity and pharynx in Uruguay. Nutr Cancer 51(2):132-139. doi:10.1207/s15327914nc5102_2

34. Zheng W, Blot WJ, Shu XO, Diamond EL, Gao YT, Ji BT, Fraumeni JF Jr (1992) Risk factors for oral and pharyngeal cancer in Shanghai, with emphasis on diet. Cancer Epidemiol Biomark Prev 1(6):441-448

35. Lijinsky W (1999) N-Nitroso compounds in the diet. Mutat Res 443(1-2):129-138

36. Jägerstad M, Skog K (2005) Genotoxicity of heat-processed foods. Mutat Res Fund Mol Mech Mutagen 574(1-2):156-172. doi:10.1016/j.mrfmmm.2005.01.030

37. Goldbohm RA, Van den Brandt PA, Dorant E (1994) Estimation of the coverage of Dutch municipalities by cancer registries and PALGA based on hospital discharge data. Tijdschr Soc Gezondheidsz 72:80-84

38. Goldbohm RA, van 't Veer P, van den Brandt PA, van 't Hof MA, Brants HA, Sturmans F, Hermus RJ (1995) Reproducibility of a food frequency questionnaire and stability of dietary habits determined from five annually repeated measurements. Eur J Clin Nutr 49(6):420-429

39. Rettig EM, D'Souza G (2015) Epidemiology of head and neck cancer. Surg Oncol Clin N Am 24(3):379-396. doi:10.1016/j. soc.2015.03.001 